\title{
INVESTIGATION OF TWO DIMENSIONAL WAKE PRESSURES DOWNSTREAM OF PERFORATED PLATES
}

\author{
Mohamed F. Yassin \\ Mining and Metallurgical Engineering Department, Faculty of \\ Engineering, Assiut University, Assiut-71516, Egypt \\ E-mail:mfy_64@yahoo.com
}

(Received July 12, 2006 Accepted July 27, 2006)

\begin{abstract}
The construction, calibration and measurements made by a built up static pressure probe for measurement of unsteady pressures in the flow field are discussed. The wind tunnel experiments were conducted on a series of two-dimensional perforated normal plates to an air stream in order to study the characteristics of unsteady wake pressures and to ascertain if they could be correlated in some way. The velocity ranged from 5 to $15 \mathrm{~m} / \mathrm{s}$ in the present study. The pressure field gets significantly modified as the perforation level increases. The present study is concerned with three plates with perforation level of 0\%, 25\% and $35 \%$. A correlation between the maximum normalized value of the mean square pressure fluctuation levels, base pressure and the perforation level of the normal plate was done.
\end{abstract}

KEYWORDS: Fluctuation pressure; Perforated plate; Wake region;

Wind tunnel

\section{NOMENCLATURE}

a constant associated with microphone

capacitance, associated with microphone

$C_{p b}$ base pressure coefficient, $\left(P_{b}-P_{\infty}\right) / 0.5 \rho U_{\infty}^{2}$

$C_{p}^{\prime} \max$

maximum fluctuating pressure coefficient

$D$ width of the two dimensional body

$\eta$ perforation of the normal plate (ratio of open to total area)

$P_{b} \quad$ mean base static pressure

$P_{\infty} \quad$ free-stream pressure

$\sqrt{\overline{p^{\prime 2}}}$ root mean square pressure fluctuation $\left(P_{r m s}^{\prime}\right)$ dynamic head

$Q \quad$ total charge

$R \quad$ resistance associated with microphone

$T_{u} \quad$ turbulence intensity 


\begin{tabular}{|c|c|}
\hline$U_{\infty}$ & free-stream velocity \\
\hline$u^{\prime}$ & fluctuating stream-wise velocity component \\
\hline$\sqrt{u^{\prime 2}}$ & root mean square velocity fluctuation $\left(u^{\prime} r m s\right)$ \\
\hline$\sqrt{u^{\prime 2}} / U_{\infty}$ & up stream turbulence intensity \\
\hline$V$ & voltage of the biasing battery, associated with microphone \\
\hline$x$ & axial distance downstream of shoulder (point of separation) \\
\hline$y$ & $\begin{array}{l}\text { vertical distance, origin of co-ordinates being at half the depth of 2-D } \\
\text { body }\end{array}$ \\
\hline$v$ & kinematic viscosity of the fluid \\
\hline & density of the fluid \\
\hline
\end{tabular}

\section{INTRODUCTION}

The wake behind an immersed body is of basic importance in applications to problems of turbulent wind interaction between structures, the dispersal of pollutants or spilt toxic material near buildings. The wind erosion of small particles such as snow and sand in regions of strong wind has been an important wind engineering problem over the past few decades. For example, atmospheric dispersion of wind-blown dust particles from open coal storage yards can cause serious air-pollution and environmental problems. Wind erosion also leads to a loss of raw materials, resulting in an unnecessary waste of costly investment.

The size of the wake and the pressure within it are the two factors which determine the magnitude of the pressure drag. The wider the wake the greater is the area over which the pressure difference between the front and rear of the body acts and hence the greater is the drag. Equally, the lower the pressure within the wake the greater is the pressure difference acting on the body and hence the drag.

The pressure fluctuations are of common occurrence in unsteady fluid flows. The need for suitable instrumentation to measure pressure fluctuations in turbulent shear flows has been of considerable interest from several years. Interest in this type of data is generated in several fields. For example, turbulent pressure fluctuations can play a significant role in cavitation, turbulent pressure fluctuations play a key role in aircraft cabin noise which perhaps was the oldest problem that warranted fluctuating pressure measurements and ways to alleviate the problem.

Further, static pressure fluctuations in interior and exterior flows, away from flow boundaries, are important in aero-acoustics and in turbulent flow descriptions. In aeroacoustics, the static pressure is of interest insofar as radiated noise is concerned, and in turbulent flows, the correlation between pressure and velocity is important in the determination of stress transport. The lack of reliable methods has severely hampered the measurement, and hence, understanding of turbulent static pressure fluctuations away from flow boundaries.

Basically, two types of pressure fluctuating measurements in turbulent flows have been attempted in the past, namely the surface and within the flow. From two review articles by Willmarth [1] and George, Benther and Arndt [2], one can understand that 
pressure fluctuation measurements pose experimental difficulties, particularly for measurements within the flow. Tsai and Yang [3] measured pressure fluctuation in the turbulent wake flow behind a two-dimensional V-gutter by use of a static pressure probe like the one used by Govinda Ram and Arakeri [4].

The detailed discussion on the construction, calibration and measurements made with a built up static pressure probe are discussed in this paper. The present study attempts to measure the fluctuating wake pressures of three, two dimensional plates with perforation level of $0 \%, 25 \%$ and $30 \%$, using a condenser microphone based static pressure probe. Some interesting results of correlating the maximum fluctuating pressures with perforation level in the wakes of perforated plates are analyzed and reported in this study.

\section{EXPERIMENTAL METHOD}

\subsection{Facility}

The facility used for the present experimental study is a suction-type low-speed wind tunnel driven by a four-bladed fan connected to a 15 HP slip-ring induction motor. Speed control of the $15 \mathrm{HP}$ slip-ring induction motor over a wide range is achieved by using a combination of stator voltage control and rotor resistance control. The cross-sectional area of the test section is $610 \mathrm{~mm} \times 610 \mathrm{~mm}$ and its length is 2100 $\mathrm{mm}$. The tunnel contraction ratio is 9:1. Several screens and a honeycomb are provided in the upstream settling chamber with a fine mull cloth cover at the bell mouth entry. The centre-line turbulence level $\left(u_{r m s}^{\prime} / U_{\infty}\right)$ was measured and found to be $0.3 \%$ within the present experimental velocity range of $5-15 \mathrm{~m} / \mathrm{s}$.

Figure 1 shows the experimental set up showing the two-dimensional test model in position and the wake region, where measurements are undertaken. The side walls of the test section had grooves to accommodate the two dimensional perforated models being tested. The verticality of the model face was checked using the plumb bob and the true horizontal level of the model using spirit level at the ends of the model, before the measurements were made.

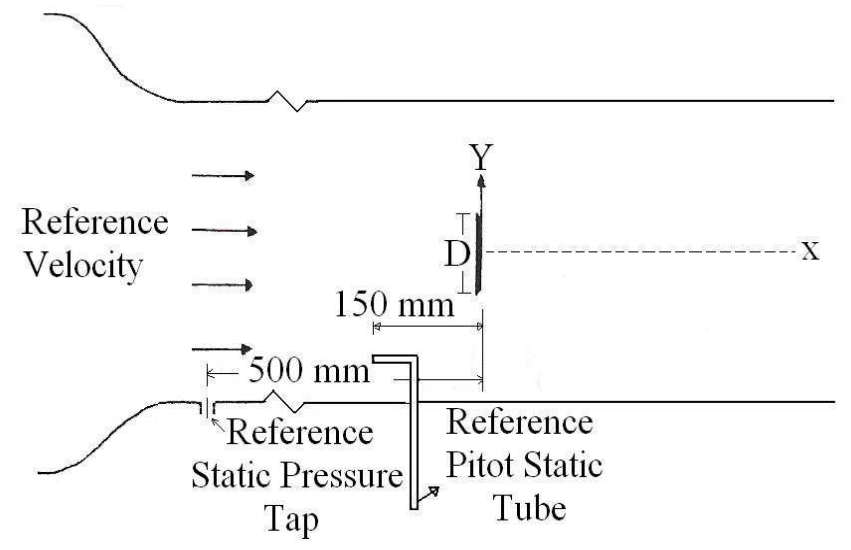

Figure 1: Experimental Set-Up. 


\subsection{Fluctuating Pressure Measurements}

\subsubsection{Microphone for sound pressure level measurements}

Microphones are transducers which detect sound signals and produce an electrical image of the sound, i.e., they produce a voltage or a current which is proportional to the sound signal. The condenser microphones work on the principle that sound pressure changes the spacing between a thin metallic membrane and the stationary back plate.

The plates are charged to a total charge, $\mathrm{Q}$

$$
Q=C V=\frac{\alpha(\text { Area of plate })(\text { Voltage })}{\text { Plate spacing }}
$$

A change in plate spacing will cause a change in charge and force a current through resistance. This current images the sound pressure, making this a pressure microphone. The condenser microphone have best overall frequency response finding wider areas of applications. The flat, faithful frequency response of the condenser microphone arises from its mechanism. Because the sensing element of a condenser microphone is a light membrane, it is capable of excellent transient response. The fact that the condenser has excellent high frequency response implies good transient response, since sharp transients have more high frequency content than the sustained sounds which follow them. The most important advantage of using the condenser microphone for measurement of fluctuating pressures in contrast to other transducers is that these possess high sensitivity. In this study the applied output is $0.75 \mathrm{mv} / \mathrm{Pa}$ for the microphone used

\subsubsection{Construction of static pressure probe}

It is important to mention here that Kobashi [5] was the first to use a static tube type pressure sensing probe with a condenser microphone as a sensing element to measure static pressure fluctuations within the flow. The frequency response of the probe was studied by means of Karman vortices produced by a circular cylinder. The Helmholtz resonance and the loss in the pressure tube were compensated electrically by a band rejection filter and high frequency booster. He used this probe in combination with a single rotary type hot wire, to measure the pressure fluctuation in the wake of a cylinder.

Further Siddon [6] made an investigation of errors induced by probe-flow interaction. He used an experimental set up with a "rotating inclined nozzle flow" to create different flow angles on a classical "static" probe geometry. A miniature condenser microphone with a low mass diaphragm to ensure good pressure sensitivity over a wide frequency range and high degree of vibration insensitivity, was housed within a probe tube in close proximity to the pressure sensing slit. A large effort has been made in developing error-compensating probe and finally he suggested that, the probe without error-compensation mechanism may be sufficiently accurate in the case of RMS pressure measurements. 
It is essential to exercise lot of care in fabricating a microphone based static pressure probe, as pointed out by several researchers. Basically, the problems stem from the need to account for the effects of the tube and the width of the air gap in front of the microphone diaphragm. The signal obtained with the probe is generally dominated by the resonant frequencies, unless the system is critically damped, in which case the signal to noise ratio suffers. By careful construction, the resonances can be shifted to higher frequencies. By trial and error, critical damping can be used by means of soft material stuffed into the tube to obtain an approximately flat frequency response curve over most of the frequency range of interest.

The static pressure fluctuations were measured with a $3.175 \mathrm{~mm}$ diameter $\mathrm{B}$ and $\mathrm{K}$ condenser microphone (Model No. 4138). The condenser microphone was supplied with a calibration chart by the manufacturer; however, its quoted sensitivity was verified with $B$ and $K$ model 4220 piston phone calibrator.

The output of the microphone was fed into a B and K model 2462 cathode follower built-in preamplifier and the root-mean-square (rms) values of the fluctuating signal were measured with a B and K model 2120 measuring amplifier/frequency analyzer. The static pressure probe used was very similar to the one used by Arndt and Nilsen [7] and also briefly described in George et al. [2]. The geometric details of the probe are shown in Fig. 2. Figure 3 presents the location of the pressure sensing holes where the effect of the nose and holder assembly nullify for the probe microphone built.

This probe microphone was calibrated against a standard microphone in an "anechoic" chamber. Figure 4 indicates the calibration set up. Preliminary calibration runs of the probe microphone clearly showed a peak in the response at about $1500 \mathrm{~Hz}$. This frequency agrees well with the predicted resonance frequency for organ type of resonance of the probe tube. Following Arndt and Nilsen [7], the resonance peak was reduced by placing glass wool as damping material. This material was placed between the face of the transducer and the static pressure sensing holes. The response of the probe with modifications was found to agree well with the standard microphone and was found to be flat within $2 \mathrm{~dB}$ over a frequency range of $20 \mathrm{~Hz}$ to $1500 \mathrm{~Hz}$ as shown in Fig. 5. The directional sensitivity of the probe microphone with respect to the sound source was also checked and up to 15 to 20 degrees tilt very small changes in the readings were observed and this is consistent with the findings of George et al. [2] with a similar probe.

The Helmholtz resonance frequency of such a configuration can be made sufficiently high as compared to the dominant frequencies associated with the turbulent pressure fluctuations.

\section{RESULTS}

To be transferred to the experimental work, the static pressure probe was traversed across the shear layer at fixed axial locations for obtaining pressure fluctuation level distribution in the wake region for various normal plates of different level of perforation. A velocity survey in the test section showed that it was uniform within $2 \%$ of the center-line velocity except for the boundary layer regions. The experiments were carried out in the velocity range of 5 to $15 \mathrm{~m} / \mathrm{s}$.

Figure 6 presents the qualitative and quantitative distribution of the fluctuating pressure in the wake region for the three levels of perforated normal plates. 
From the analysis of results it appears, that maximum pressure fluctuation levels in the flow field can be correlated well with the base pressure and level of perforation. For the present study it is found that the ratio $\left[C_{P}^{\prime} \max /-C_{P b}(1-\eta)\right]$ bears a constant value.

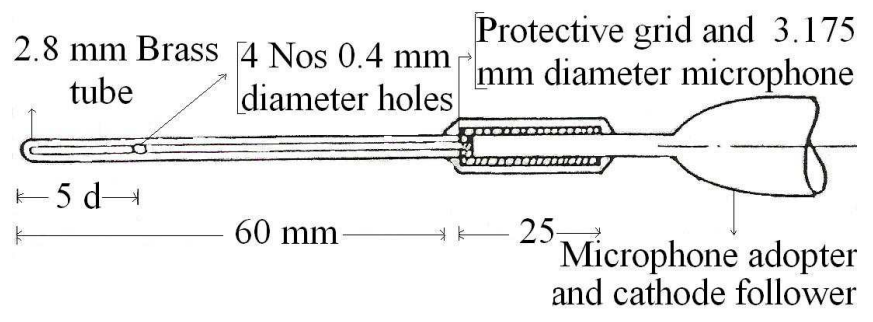

Figure 2: Geometry of the Probe Microphone.

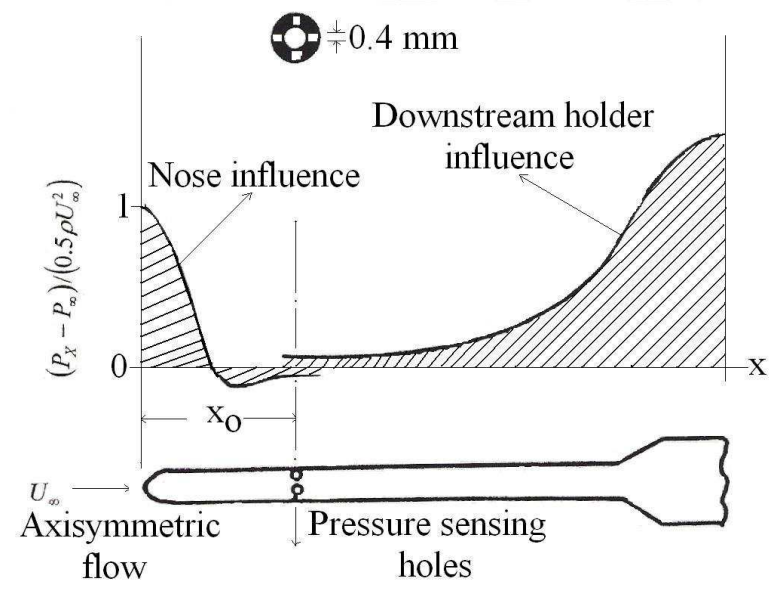

Figure 3: Nose and Holder Influence on the Static Pressure Probe.

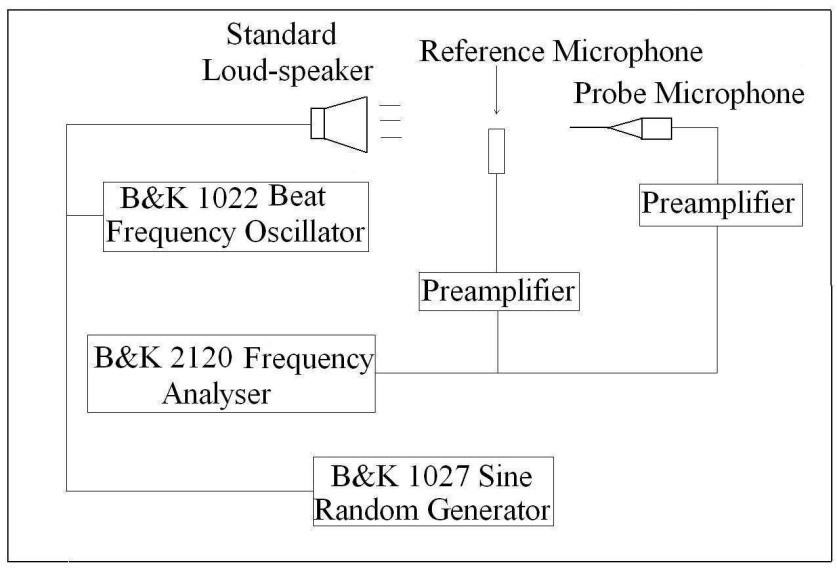

Figure 4: Layout of the Probe Microphone Calibration Set-Up. 


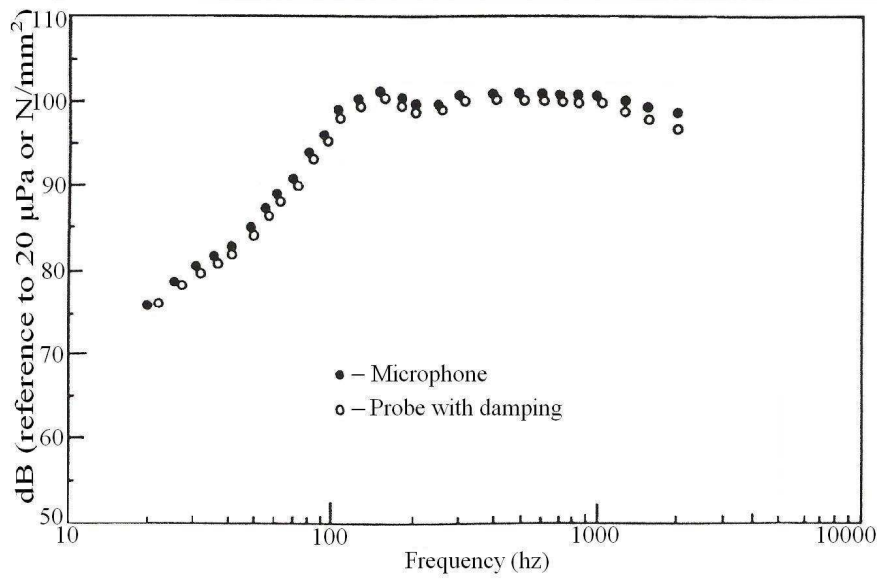

Figure 5: Frequency Response of the Microphone for a Particular Loud-Speaker Output.

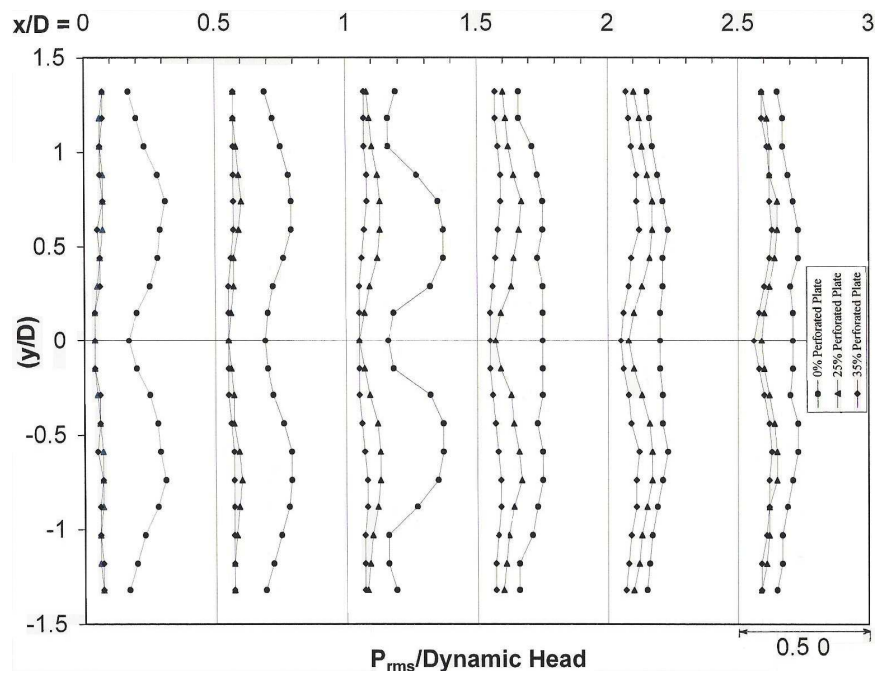

Figure 6: The Qualitative and Quantitative Distribution of the Fluctuating Pressure in the Wake for Three Perforation Levels ( $0 \%, 25 \%$ and $35 \%)$.

\section{CONCLUSION}

The fluctuating pressure measurements in the wake region are shown to be strongly dependent on the perforation level of the normal plate, indicating their importance of measurement. Analyses of the results show that, the maximum pressure fluctuation levels in the wake can be correlated well with the base pressure and perforation level. For the present study it is found that the ratio $\left[C_{P}^{\prime} \max /-C_{P b}(1-\eta)\right]$ appears to be constant and is found to be equal to 0.30 . The findings of this paper can be used for solving the problem of turbulent wind interaction between structures, the dispersal of pollutants or spilt toxic material near buildings. 


\section{REFERENCE}

[1] Willmarth, W. W., 1975, "Pressure Fluctuations Beneath a Turbulent Boundary Layer," Ann. Rev. of Fluid Mech., Vol. 7, pp. 13-38.

[2] George, W. K., Benther, P. D. and Arndt, R. E. A., 1984, "Pressure Spectra in Turbulent Free Shear Flows," Journal of Fluid Mech., Vol. 148, pp. 155-191.

[3] Tsai, G.L. and Yang, J. T., 1993, "Pressure Fluctuation in Correlation with Velocity Fluctuations in Turbulent Wake Flow," pp. 462-463.

[4] Govinda Ram, H. S. and Arakeri, V. H., 1990, "Studies on Unsteady Pressure Fields in the Region of Separating and Reattaching Flows," Journal of Fluids Engineering, Vol. 112, pp. 402-408.

[5] Kobashi, Y., 1957, "Measurements of Pressure Fluctuation in the Wake of Cylinder," Journal of the Physical Society of Japan, Vol. 12(5), pp. 533-543.

[6] Siddon, T. E., 1968, "On the Response of Pressure Measuring Instrumentation in Un-steady Flow", University Toronto Inst. Aerospace Report 136.

[7] Arndt, R. E. A. and Nilsen, A. W., 1971, "On the Measurement of Fluctuating Pressure in the Mixing Zone of a Round Jet," ASME Fluids Engineering Division, Paper No. 71-FE-31.

\section{دراسة ثنائية الأبعاد للضغوط على الألواح المثقبة}

أجريت هذه الدر اسـة بغرض معرفة العلاقة بين مستوى تذبـب الضـغوط على مستوى

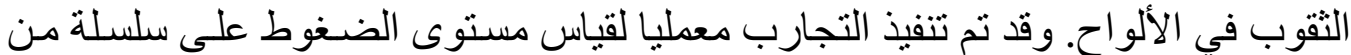
الألو اح الطبيعية المنقبة ثنائية الأبعاد وبمستوى تثقيب صفر ، 25\%، 35 \%

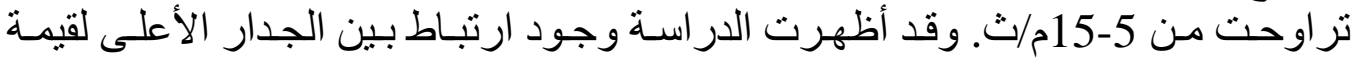

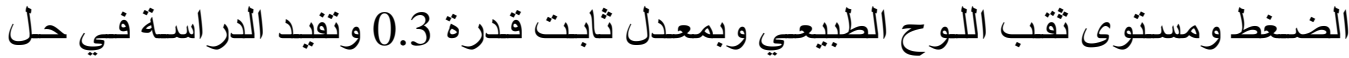
مشاكل تقاطعات الرياح المضربة وانتشار الملوثات القريبة من المباني. 